\title{
Effects of various factors on prostaglandin synthesis by the guinea-pig uterus
}

\author{
N. L. Poyser \\ Department of Pharmacology, University of Edinburgh Medical School, I George Square, \\ Edinburgh EH8 9JZ, U.K.
}

\begin{abstract}
Summary. Phospholipases (PL) A-2 and C stimulated the outputs of prostaglandin (PG) F-2 $\alpha$, PGE-2 and 6-keto-PGF-1 $\alpha$ from the Day-7 and Day-15 guinea-pig uterus superfused in vitro. PLC had a more pronounced effect than PLA-2, particularly on the output of PGE-2. The ratios of the outputs of PGF-2 $\alpha$ and PGE-2 were similar after stimulation by A23187 and PLA-2, but this ratio was lower after stimulation by PLC. It appears that the stimulation of endometrial PGF-2 $\alpha$ synthesis by $\mathrm{Ca}^{2+}$ is via activation of PLA-2 rather than via activation of PLC, although the PLC used was of bacterial origin (which uses phosphatidylcholine as substrate) rather than of mammalian origin (which uses phosphatidylinositol as substrate).

Forskolin (which increased endometrial and myometrial cyclic AMP levels) and phorbol 12-myristate-13-acetate had no effect on uterine PG output, indicating that cyclic AMP and protein kinase $\mathrm{C}$ are not involved in the stimulation of endometrial PGF-2 $\alpha$ synthesis in the guinea-pig. Uterine PG output was not stimulated by $54 \mathrm{~mm}-$ $\mathrm{KCl}$, which shows that the pulsatile nature of endometrial PGF- $2 \alpha$ synthesis and release is not due to an intermittent, synchronous depolarization of the endometrial cells.
\end{abstract}

\section{Introduction}

Prostaglandin (PG) F-2 $\alpha$ has been identified as the uterine luteolytic hormone in several nonprimate, mammalian species (see Horton \& Poyser, 1976; Poyser, 1981). In the guinea-pig, PGF-2 $\alpha$ output from the uterus increases from Day 11 of the cycle (Blatchley et al., 1972; Earthy et al., 1975; Antonini et al., 1976). Studies on the guinea-pig uterus superfused in vitro have shown that the outputs of PGF-2 $\alpha$, PGE-2 and 6-keto-PGF-1 $\alpha$ increase 21.9-, 1.8- and 2.9-fold, respectively, between Days 7 and 15 of the cycle (Poyser \& Brydon, 1983), and that oestradiol acting on a progesterone-primed uterus is responsible for this relatively specific increase in PGF-2 $\alpha$ output (Poyser, 1983a). Oestradiol output from the guinea-pig ovary increases from Day 10 of the cycle (Joshi et al., 1973), which is consistent with oestradiol being responsible for the stimulation of uterine PGF-2 $\alpha$ output from Day 11. Since PGs are not stored in tissues, oestradiol has to initiate a sequence of biochemical processes in the endometrium which culminate in the relatively specific synthesis and release of PGF-2 $\alpha$. The present study has investigated some of the possible intracellular factors which may be involved in this stimulation of endometrial PGF- $2 \alpha$ production.

\section{Materials and Methods}

Virgin guinea-pigs weighing $650-950 \mathrm{~g}$ were examined daily and a vaginal smear was taken when the vagina was perforate. The first day of the cycle was taken as the day preceding the post-ovulatory influx of leucocytes when cornification was at a maximum. All 70 guinea-pigs used had normal cycles. They were killed by stunning and incising the neck on Day 7 or Day 15 of the cycle, and were used in one of the following experiments. 
Experiment 1: superfusion studies. The two uterine horns in each of 60 guinea-pigs were removed, weighed and opened by cutting longitudinally. Each uterine horn was suspended in an organ bath and attached to an isotonic lever under a load of $2 \mathrm{~g}$. Both uterine horns were superfused independently with Krebs' solution (5 ml/min; for composition, see Mitchell et al., 1977) at $37^{\circ} \mathrm{C}$, pre-gassed with $5 \% \mathrm{CO}_{2}-95 \% \mathrm{O}_{2}$. After an initial settling period of $60 \mathrm{~min}$, samples of superfusate were collected for 10 -min periods consecutively over the next 80 or 90 min $(8$ or 9 samples/uterine horn). Additions of phospholipase (PL) A-2 (2 U/ml), PLC ( $2 \mathrm{U} / \mathrm{ml})$, forskolin (10 $\mu \mathrm{M})$, phorbol 12 myristate-13-acetate (TPA; $81 \mathrm{nM}), \mathrm{A} 23187$ (382 nM) and $\mathrm{KCl}(56 \mathrm{~mm}$ ) were made to the Krebs' solution, before it was superfused over the tissues, during the collection of Samples 4 and 5 or $4-6$ (5 guinea-pigs/experiment). One uterine horn from each animal served as a control for the other horn.

After collection, the $\mathrm{pH}$ of each sample was lowered to 4.0 with $\mathrm{HCl}$ and the $\mathrm{PGs}$ were extracted by shaking twice with $50 \mathrm{ml}$ ethyl acetate. The two ethyl acetate fractions were combined and evaporated to dryness at $50^{\circ} \mathrm{C}$ on a rotary evaporator. Each extract was redissolved in $10 \mathrm{ml}$ ethyl acetate and stored at $-20^{\circ} \mathrm{C}$ before the amounts of PGF-2 $\alpha$, PGE-2 and 6-keto-PGF-1 $\alpha$ present were measured by radioimmunoassay. The recoveries of PGF-2 $\alpha$ and PGE-2 are $>90 \%$ and the recovery of 6-keto-PGF-1 $\alpha$ is $>80 \%$ by this method (Poyser \& Scott, 1980; Swan \& Poyser, 1983). The results are not corrected for recovery.

Experiment 2: cyclic AMP production. The two uterine horns in each of 10 guinea-pigs were removed and opened by cutting longitudinally. For each uterine horn, the endometrium was dissected away from the myometrium by cutting away $1 \times 2 \mathrm{~mm}$ pieces of endometrium. The myometrium was then cut into pieces of similar size. The endometrial and myometrial tissue from each uterine horn were weighed and then each placed in $10 \mathrm{ml} \mathrm{Krebs}$ solution (pre-gassed with $5 \% \mathrm{CO}_{2}-95 \% \mathrm{O}_{2}$ ) containing $0.05 \mathrm{~mm}$-3-isobutyl-1-methyl-xanthine. Forskolin (10 $\left.\mu \mathrm{M}\right)$ was added to the endometrial and myometrial samples from one uterine horn of each animal. The 4 tissue samples from each guinea-pig were incubated for $20 \mathrm{~min}$ at $37^{\circ} \mathrm{C}$, and then $20 \mathrm{ml}$ ethanol were added to stop the reaction. Each tissue sample was homogenized in the ethanolic solution, and then centrifuged at $2500 \mathrm{~g}$ for $10 \mathrm{~min}$. Each ethanolic extract was evaporated to dryness on a rotary evaporator at $50^{\circ} \mathrm{C}$, and the dry extract was stored at $-20^{\circ} \mathrm{C}$ before its content of cyclic AMP was measured. Recovery of cyclic AMP by this method is $>85 \%$ (Armstrong et al., 1985). The results are not corrected for recovery.

Assays. PGF-2 $\alpha$, PGE-2 and 6-keto-PGF-1 $\alpha$ were measured using antibodies raised in rabbits and tested in this laboratory (Dighe et al., 1975; Poyser, 1980; Poyser \& Scott, 1980; Lytton \& Poyser, 1982). The only significant crossreactivities are PGE-1 (66\%), PGA-2 $(26 \%)$ and PGB-2 $(12 \%)$ with the PGE-2 antiserum, and PGF-1a $(28 \%)$ with the PGF-2 $\alpha$ antiserum. Previous studies involving analysis by gas chromatography and mass spectrometry have shown that the guinea-pig uterus synthesizes very little PGF-1 $\alpha$ in comparison with PGF-2 $\alpha$, and that there is no detectable synthesis of PGE-1, PGA-2 and PGB-2 (Poyser, 1983b). It is likely, therefore, that the PGF-2 $\alpha$ and PGE-2 antibodies were measuring predominantly the PG to which they had been raised. The intra-assay coefficients of variation were $6.3 \%$ (PGF-2 $\alpha$ ), $8 \cdot 2 \%$ (PGE-2) and 7.6\% (6-keto-PGF-1 $\alpha$ ). The inter-assay coefficients of variation were $8 \cdot 1 \%$ (PGF-2 $\alpha$ ), 8.5\% (PGE-2) and 7.8\% (6-keto-PGF-1 $\alpha$ ). The limits of detection were $30 \mathrm{pg}$ PGF-2 $\alpha, 40 \mathrm{pg}$ PGE-2 and $30 \mathrm{pg}$ 6-keto-PGF-1 $\alpha$ per assay tube for the respective assays.

Cyclic AMP was measured by the method of Armstrong et al. (1985) using a specific cyclic AMP binding protein. The intra-assay and inter-assay coefficients of variation were $6.1 \%$ and $10 \cdot 1 \%$, respectively. The sensitivity of the assay was $0.6 \mathrm{pmol}$ per assay tube.

Sources of materials. PLA-2 (EC 3.1.1.4; from Naja naja venom), PLC (EC 3.1.4.3; from Clostridium perfringens), forskolin (stimulates adenyl cyclase), A23187 (a calcium ionophore), TPA (stimulates protein kinase C) and 3isobutyl-1-methyl-xanthine (a phosphodiesterase inhibitor) were purchased from Sigma Chemical Co., Poole, Dorset, U.K. Cyclic AMP binding protein was purchased from BDH Chemicals Ltd, Poole, Dorset, U.K.

Statistical tests. Changes in the output of a particular PG with time were analysed by Duncan's multiple range test. However, if the variances of some of the groups were unequal by the variance $F$ ratio test, changes in output were analysed by the paired $t$ test. Other comparisons were made using the paired $t$ test.

\section{Results}

\section{Experiment 1: superfusion studies}

PLA-2 and PLC significantly stimulated $(P<0.05)$ the outputs of PGF-2 $\alpha$, PGE-2 and 6-ketoPGF- $1 \alpha$ from both the Day-7 and Day-15 guinea-pig uterus (Figs $1 \& 2$ ). Although the same 'unit activity' of both enzymes was used, PLC caused a greater stimulation of PG output, particularly as regards the output of PGE-2.

Forskolin, TPA and $\mathrm{KCl}$ had no effect on basal PG output, and TPA had no effect on A23187stimulated PG output from the Day-7 and Day-15 guinea-pig uterus (Figs 3, 4, $5 \& 6$ ). The output of 6-keto-PGF-1 $\alpha$ from the Day-7 uterus, and the outputs of PGF-2 $\alpha$, PGE-2 and 6-keto-PGF-1 $\alpha$ 
(a) Day 7

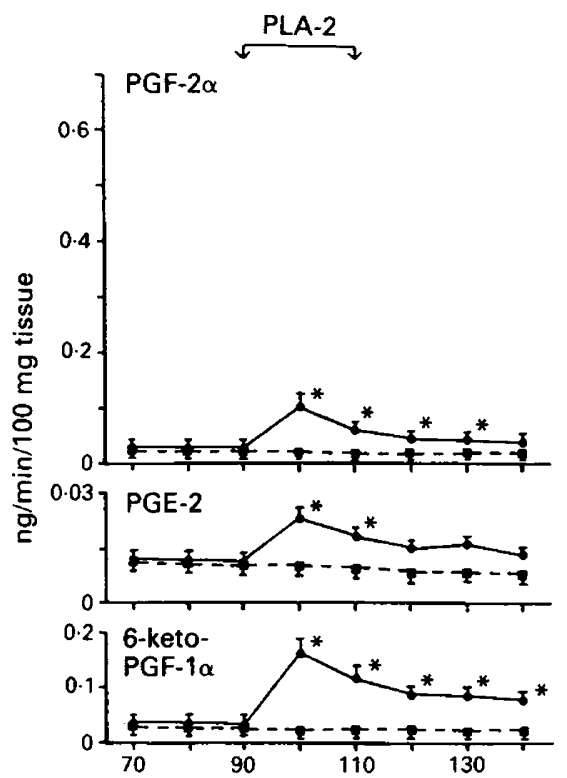

(b) Day 15
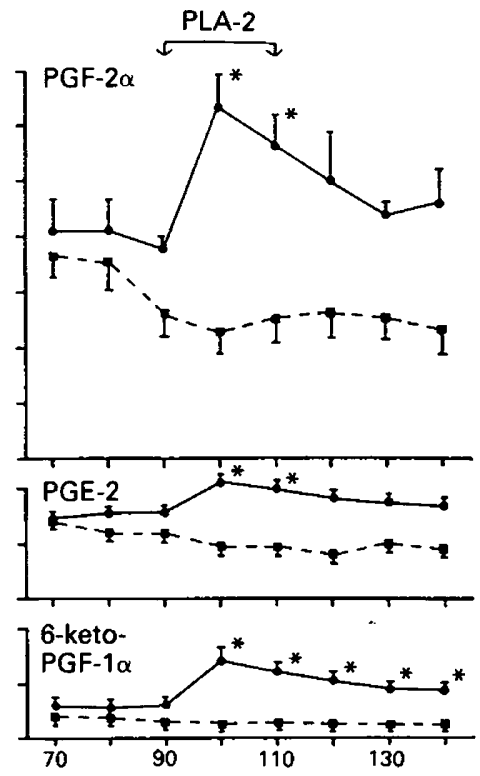

Minutes

Fig. 1. Mean ( \pm s.e.m., $n=5$ ) outputs of prostaglandin (PG) F-2 $\alpha$, PGE-2 and 6-keto-PGF-1 $\alpha$ from Day-7 and Day-15 guinea-pig uterine horns treated (solid line) as indicated or not treated (broken line) with phospholipase (PL) A-2 $(2 \mathrm{U} / \mathrm{ml}) .{ }^{*}$ Significantly higher $(P<0.05)$ after PLA-2 treatment for any one PG on the same day.
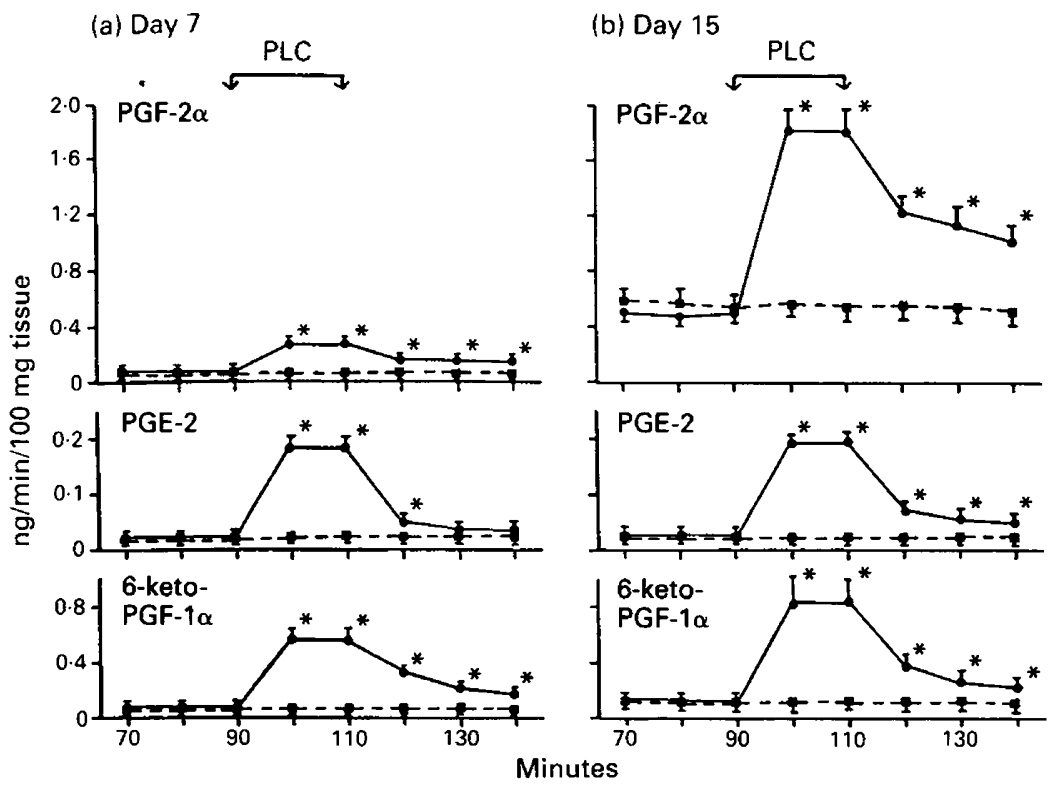

Fig. 2. Mean ( \pm s.e.m., $n=5$ ) outputs of prostaglandin (PG) F-2 $\alpha$, PGE-2 and 6-keto-PGF-1 $\alpha$ from Day-7 and Day-15 guinea-pig uterine horns treated (solid line) as indicated or not treated (broken line) with phospholipase (PL) C $(2 \mathrm{U} / \mathrm{ml})$. *Significantly higher $(P<0.05)$ after PLC treatment for any one PG on the same day. 
(a) Day 7

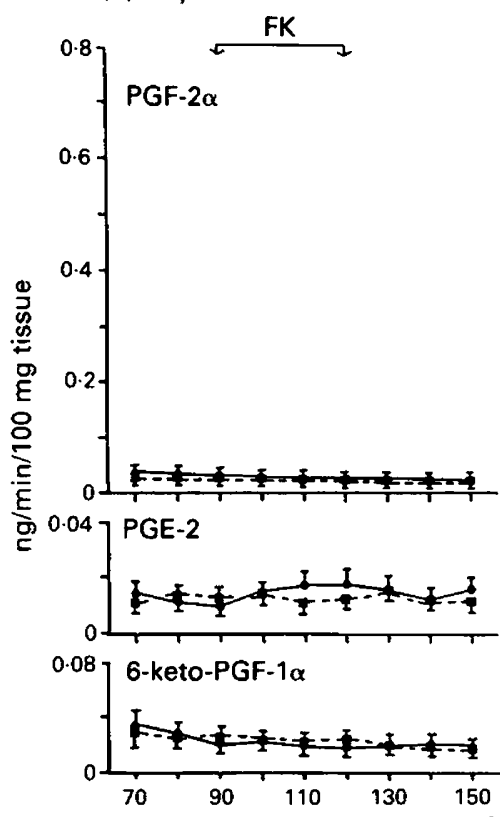

(b) Day 15

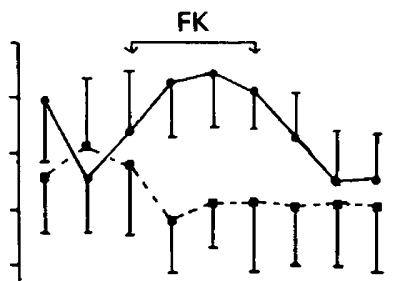

PGF-2 $\alpha$

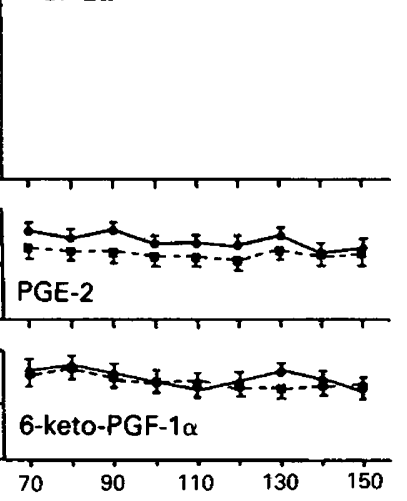

Fig. 3. Mean ( \pm s.e.m., $n=5$ ) outputs of prostaglandin (PG) F-2 $\alpha$, PGE-2 and 6-keto-PGF-1 $\alpha$ from Day-7 and Day-15 guinea-pig uterine horns treated (solid line) as indicated or not treated (broken line) with forskolin (FK; $10 \mu \mathrm{M}$ ).

(a) Day 7

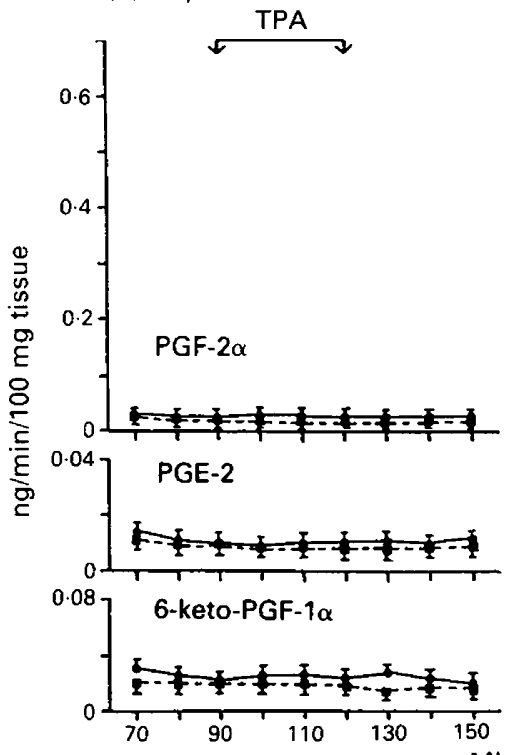

(b) Day 15

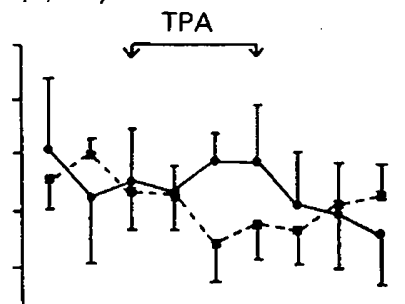

PGF-2 $\alpha$

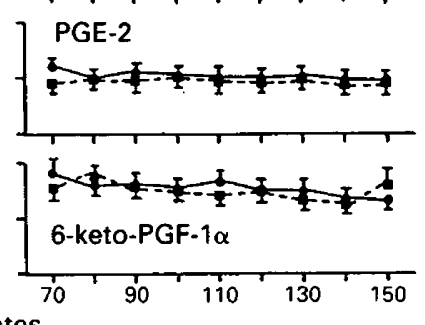

Fig. 4. Mean ( \pm s.e.m., $n=5$ ) outputs of prostaglandin (PG) F-2 $\alpha$, PGE-2 and 6-keto-PGF-1 $\alpha$ from Day-7 and Day-15 guinea-pig uterine horns treated (solid line) as indicated or not treated (broken line) with phorbol 12-myristate-13-acetate (TPA; $81 \mathrm{nM}$ ). 
(a) Day 7

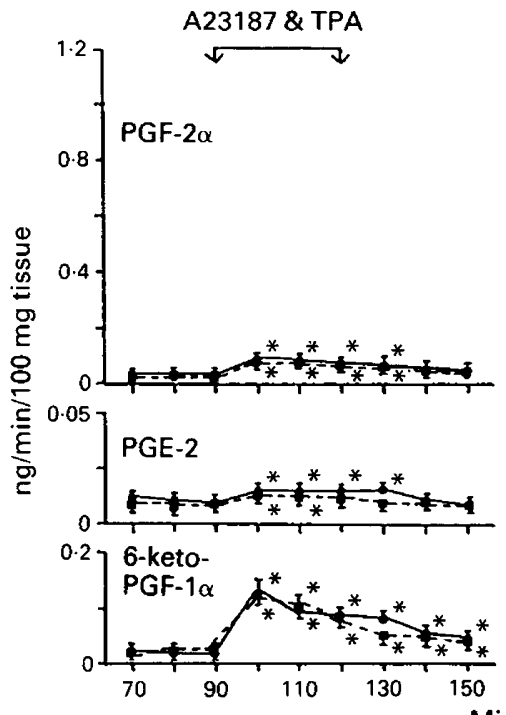

(b) Day 15

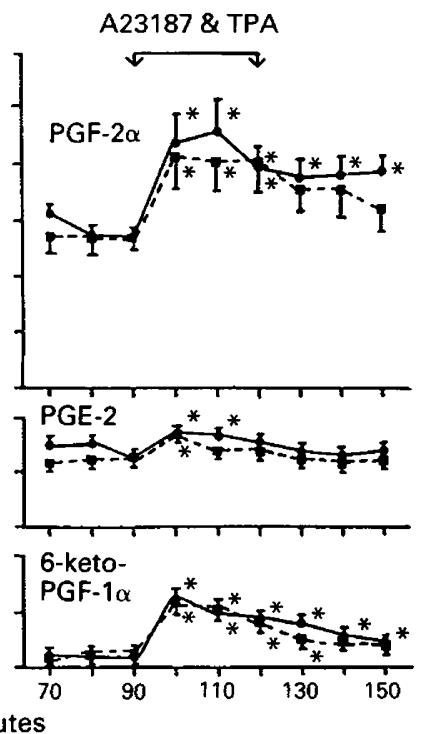

Fig. 5. Mean ( \pm s.e.m., $n=5$ ) outputs of prostaglandin (PG) F-2 $\alpha$, PGE-2 and 6-keto-PGF-1 $\alpha$ from Day-7 and Day-15 guinea-pig uterine horns treated with A23187 (382 nM) as indicated, and treated (solid line) as indicated or not treated (broken line) with phorbol 12-myristate-13acetate (TPA; $81 \mathrm{nM})$. *Significantly higher $(P<0.05)$ after A23187 treatment for any one PG from one set of uterine horns on the same day.

(a) Day 7

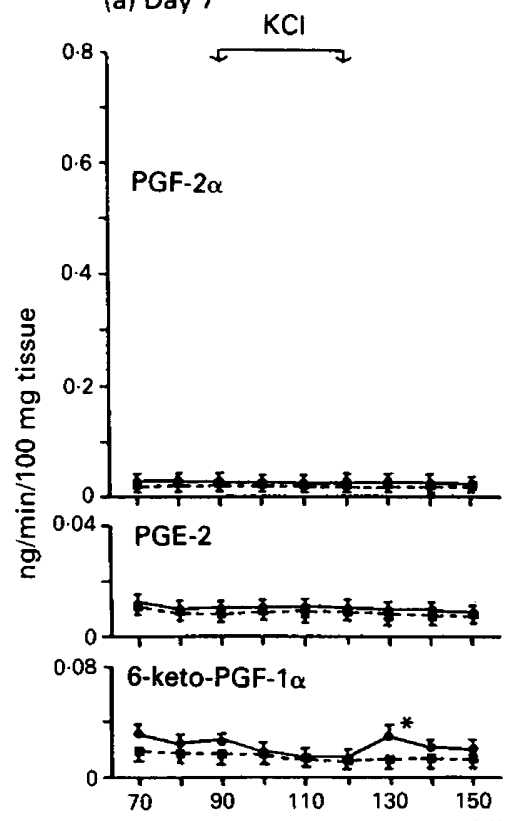

(b) Day 15

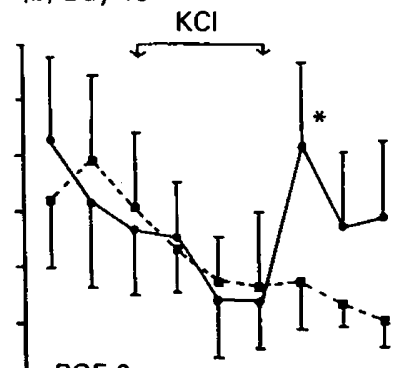

PGF-2 $\alpha$

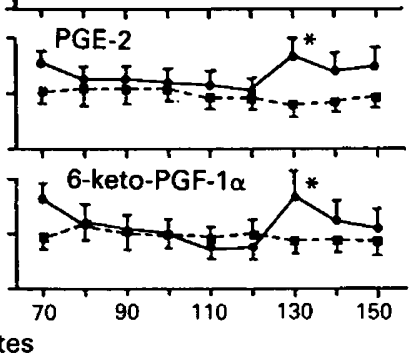

Fig. 6. Mean ( \pm s.e.m., $n=5$ ) outputs of prostaglandin (PG) F-2 $\alpha$, PGE-2 and 6-keto-PGF-1 $\alpha$ from Day-7 and Day-15 guinea-pig uterine horns treated (solid line) as indicated or not treated (broken line) with $\mathrm{KCl}(56 \mathrm{nM})$. *Significantly higher $(P<0.05)$ after the cessation of $\mathrm{KCl}$ treatment for any one PG on the same day. 
Table 1. Mean ( \pm s.e.m., $n=5$ ) concentrations of cyclic AMP in Day-7 and Day-15 guinea-pig endometrium and myometrium in the absence (C) and presence $(\mathrm{T})$ of forskolin $(10 \mu \mathrm{M})$

\begin{tabular}{|c|c|c|c|c|}
\hline & \multicolumn{4}{|c|}{ pmol cyclic AMP $/ 100 \mathrm{mg}$ tissue $/ 20 \mathrm{~min}$} \\
\hline & \multicolumn{2}{|c|}{ Day 7} & \multicolumn{2}{|c|}{ Day 15} \\
\hline & $\mathrm{C}$ & $T$ & $\mathrm{C}$ & $\mathrm{T}$ \\
\hline $\begin{array}{l}\text { Endometrium } \\
\text { Myometrium }\end{array}$ & $\begin{array}{l}0.18 \pm 0.04 \\
1.61+0.40 \div\end{array}$ & $\begin{array}{r}10.29 \pm 1.00^{*} \\
9.82 \pm 0.86^{*}\end{array}$ & $\begin{array}{l}0.19 \pm 0.05 \\
1.47+0.34 t\end{array}$ & $\begin{array}{r}9.22 \pm 1.42^{*} \\
10.19+1.70^{*}\end{array}$ \\
\hline
\end{tabular}

*Significantly higher $(P<0.01)$ than corresponding control $(C)$ value for the same tissue on the same day.

† Significantly higher $(P<0.02)$ than the control $(C)$ value for endometrium on the same day.

from the Day-15 uterus significantly $(P<0.05)$, but transiently, increased after stopping the $\mathrm{KCl}$ treatment (Fig. 6). PLA-2, PLC, A23187 and $\mathrm{KCl}$ caused the uterine horns to contract.

\section{Experiment 2: cyclic AMP production}

Basal cyclic AMP levels did not differ in the endometrium or myometrium between Days 7 and 15 of the cycle. However, basal cyclic AMP levels were 8- to 9-fold higher in the myometrium than in the endometrium. Forskolin significantly increased $(P<0.01)$ cyclic AMP levels in the endometrium and myometrium to the same extent on Days 7 and 15 of the cycle (Table 1).

\section{Discussion}

The calcium ionophore, A23187, stimulates the outputs of PGF-2 $\alpha$, 6-keto-PGF-1 $\alpha$ and, to a lesser extent, PGE-2 from the Day-7 and Day-15 guinea-pig uterus superfused in vitro (Poyser \& Brydon, 1983), an action which is dependent upon the presence of extracellular $\mathrm{Ca}^{2+}$ (Poyser, 1984). The endometrium and myometrium are the major sites of PGF-2 $\alpha$ and 6-keto-PGF-1 $\alpha$ synthesis, respectively (Poyser, 1983b). The high output of PGF-2 $\alpha$ from Day-15 guinea-pig endometrium maintained in tissue culture is dependent upon the presence of extracellular $\mathrm{Ca}^{2+}$ (Riley \& Poyser, 1987). It is clear that $\mathrm{Ca}^{2+}$ is one factor involved in the stimulation of endometrial PGF-2 $\alpha$ synthesis by the ovarian steroid hormones. Vogt (1978) proposed that the activation of PLA-2 by $\mathrm{Ca}^{2+}$ (since PLA-2 causes the release of arachidonic acid from phospholipids) was the rate-limiting step in PG synthesis by tissues. However, Bell et al. (1979) proposed that arachidonic acid for PG synthesis was released from phosphatidylinositol by the sequential action of PLC and diglyceride lipase. The present study has shown that both PLA-2 and PLC stimulate PG output from the Day-7 and Day-15 uterus, although the bacterial PLC used prefers phosphatidylcholine (PC) rather than phosphatidylinositol as substrate. Nevertheless, this study has shown that diglyceride formed from phospholipid by PLC can be acted upon to release arachidonic acid for PG synthesis in the uterus. A phosphatidylinositol-specific PLC is present in some mammalian tissues (see Clark et al., 1986). Consequently, the question is raised as to whether PLA-2 or PLC is involved in endometrial PGF- $2 \alpha$ synthesis.

The PLA-2 and PLC used had different effects on uterine PG output. Firstly, although the same unit activity of both enzymes was used, PLC caused the greater stimulation of PG synthesis. Secondly, PLC had a greater effect on PGE-2 production. The ratios of the outputs of PGF-2 $\alpha$ and PGE-2 stimulated by PLA-2 were $4 \cdot 1: 1 \cdot 0$ and $19 \cdot 8: 1 \cdot 0$ on Days 7 and 15, respectively. The ratios after stimulation by PLC were $1 \cdot 2: 1.0$ and $9 \cdot 5: 1.0$ on Days 7 and 15 , respectively. A23187 stimulation of the uterus produced PGF- $2 \alpha$ to PGE-2 ratios of 4:8:1.0 and 21.6:1.0 on Days 7 and 15 , respectively. Consequently, the stimulation of PGF-2 $\alpha$ and PGE-2 outputs by $\mathrm{Ca}^{2+}$ and PLA-2 are 
similar, while the stimulation produced by PLC is different. Little of the endogenous arachidonic acid released by $\mathrm{Ca}^{2+}$ and PLA-2 is converted to PGE-2, while much more of the arachidonic acid released by PLC is transformed into PGE-2. Consequently, there appear to be different endogenous pools of arachidonic acid released by PLA- 2 and PLC, and the pool released by PLA-2 appears to be similar to the pool released by $\mathrm{Ca}^{2+}$. The greater stimulation of PGE-2 by PLC is similar to that observed by using exogenous arachidonic acid (Poyser, 1985). Overall, the present findings are more consistent with the activation of PLA-2 by $\mathrm{Ca}^{2+}$, rather than the activation of PLC, being involved in the synthesis of PGF-2 $\alpha$ in the guinea-pig uterus. In addition, there is very little stimulation of uterine PGE-2 output by oestradiol acting on a progesterone-primed uterus (Poyser \& Brydon, 1983; Poyser, 1983a), indicating that PLA-2 and not PLC is involved in the stimulation of PGF-2 $\alpha$ output by the ovarian steroid hormones. This conclusion is in agreement with the previous report that PLA-2 rather than PLC is the main enzyme involved in arachidonic acid liberation in platelets (Imai et al., 1982). However, the increase in free arachidonic acid concentration induced by oxytocin in human endometrium may be the result of PLC acting on phosphatidylinositol (Schrey et al., 1986). Consequently, the profile of PG output from the guinea-pig uterus after treatment with a phosphatidylinositol-specific mammalian PLC is merited once this enzyme becomes commercially available.

Forskolin stimulated the formation of cyclic AMP in the endometrium and myometrium from Day-7 and Day-15 guinea-pigs. However, forskolin had no effect on uterine PG output indicating that cyclic AMP is not involved in the stimulation of endometrial PGF- $2 \alpha$ synthesis and release. TPA also had no effect on uterine PG output showing that protein kinase $C$ does not stimulate endometrial PGF-2 $\alpha$ production in the guinea-pig. This finding is consistent with the lack of effect of TPA on PGF-2 $\alpha$ output from Day-7 and Day-15 guinea-pig endometrium maintained in culture for 3 days (Riley \& Poyser, 1987). However, TPA stimulates PGF-2 $\alpha$ synthesis by human endometrial cells in culture (Skinner et al., 1984), probably by stimulating PLA-2 (Schrey \& Read, 1986), indicating that differences exist in the intracellular factors controlling PGF- $2 \alpha$ production by guinea-pig and human endometrium.

Protein kinase $\mathrm{C}$ has been reported to potentiate the intracellular actions of $\mathrm{Ca}^{2+}$ (see Berridge \& Irvine, 1984). Thromboxane A-2 production by platelets in response to calcium ionophore is potentiated by TPA (Mobley \& Tai, 1985). However, TPA had no effect on the stimulation of PG output from the guinea-pig uterus by A23187. Protein kinase $\mathrm{C}$ therefore does not potentiate the stimulatory effect of $\mathrm{Ca}^{2+}$ on uterine PG production in the guinea-pig.

Studies on the larger, non-primate mammalian species (e.g. sheep) have shown that increased PGF- $2 \alpha$ output from the endometrium is not continuous but occurs as pulses (see Horton \& Poyser, 1976). To obtain a pulse, a synchronous synthesis of PGF-2 $\alpha$ by the endometrial cells is required. One method by which a synchronous stimulation of cells is achieved in biological systems is by a progressive and rapid depolarization via cell-to-cell contacts. However, depolarization with $\mathrm{K}^{+}$, although causing the uterus to contract, failed to stimulate endometrial PGF- $2 \alpha$ synthesis and release. An intermittent synchronous depolarization is therefore not responsible for the pulsatile nature of endometrial PGF- $2 \alpha$ production.

This study was supported by a grant from the SERC. I thank Dr Roma Armstrong for performing the cyclic AMP assays, and Miss Lorna Marshall for technical assistance. Authentic PGs were kindly supplied by the Upjohn Co., Kalamazoo, Michigan, U.S.A.

\section{References}

Antonini, R., Turner, T.T. \& Pauerstein, C.J. (1976) The hormonal control of the guinea-pig corpus luteum during early pregnancy. Fert. Steril. 27, 1322-1325.

Armstrong, R.A., Jones, R.L., Peesapati, V., Will, S.G. \& Wilson, N.H. (1985) Competitive antagonism at thromboxane receptors in human platelets. $B r . J$. Pharmac. 84, 595-607.

Berridge, M.J. \& Irvine, R.F. (1984) Inositol triphosphate, a novel second messenger in cellular signal transduction. Nature, Lond. 312, 315-321. 
Blatchley, F.R., Donovan, B.T., Horton, E.W. \& Poyser, N.L. (1972) The release of prostaglandins and progestin into the utero-ovarian venous blood of guinea-pigs during the oestrous cycle and following oestrogen treatment. J. Physiol., Lond. 222, 69-88.

Bell, R.L., Kennerley, D.A., Stanford, N. \& Majerus, P.W. (1979) Diglyceride lipase: a pathway for arachidonate release from human platelets. Proc. natn. Acad. Sci. U.S.A. 76, 3238-3241.

Clark, M.A., Shorr, R.G.L. \& Bromalaski, J.S. (1986) Antibodies prepared to Bacillus cereus phospholipase $\mathrm{C}$ cross-react with a phosphatidylcholine preferring phospholipase $\mathrm{C}$ in mammalian cells. Biochem. Biophys. Res. Commun. 140, 114-119.

Dighe, K.K., Emslie, H.A., Henderson, L.K., Rutherford, F. \& Simon, L. (1975) The development of antisera to prostaglandins $B_{2}$ and $F_{2 \alpha}$ and their analysis using solid-phase and double antibody radioimmunoassay methods. Br. J. Pharmac. 55, 503-514.

Earthy, M., Bishop, C. \& Flack, J.D. (1975) Progesterone and prostaglandin $\mathrm{F}$ concentrations in utero-ovarian venous plasma of cyclic guinea-pigs. J. Endocr. 64, $11 P-12 P$.

Horton, E.W. \& Poyser, N.L. (1976) Uterine luteolytic hormone: a physiological role for prostaglandin $\mathrm{F}_{2 a}$. Physiol. Rev. 56, 595-561.

Imai, A., Yano, K., Kameyama, Y. \& Nozawa, Y. (1982) Evidence for predominance of phospholipase $A_{2}$ in release of arachidonic acid in thrombin-stimulated platelets. Phosphatidylinositol-specific phospholipase $\mathrm{C}$ may play a minor role in arachidonate liberation. Jap. J. exp. Med. 52, 99 106.

Joshi, H.S., Watson, D.J. \& Labhsetwar, A.P. (1973) Ovarian secretion of oestradiol, oestrone, 20-dihydroprogesterone and progesterone during the oestrous cycle of the guinea-pig. J. Reprod. Fert. 35, 177-182.

Lytton, F.D.C. \& Poyser, N.L. (1982) Concentration of PGF-2 $\alpha$ and PGE-2 in the uterine venous blood of rabbits during pseudopregnancy and pregnancy. $J$. Reprod. Fert. 64, 621-629.

Mitchell, S., Poyser, N.L. \& Wilson, N.H. (1977) Effect of $p$-bromophenacyl bromide, an inhibitor of phospholipase $A_{2}$, on arachidonic acid release and prostaglandin synthesis by the guinea-pig uterus. $B r . J$. Pharmac. 59, 107-113.

Mobley, A. \& Tai, H.-H. (1985) Synergistic stimulation of thromboxane biosynthesis by calcium ionophore and phorbol ester or thrombin in human platelets. Biochem. Biophys. Res. Commun. 130, 717-723.

Poyser, N.L. (1980) Development and use of radioimmunoassay for measuring 6-oxo-prostaglandin $F_{1 a}$. In Prostaglandins, Prostacyclin and Thromboxane Measurement, pp. 44-45. Eds J. M. Boeynaems \& A. G. Herman. Martinus Nijhoff, The Hague.
Poyser, N.L. (1981) Prostaglandins in Reproduction. John Wiley \& Sons Ltd, Chichester.

Poyser, N.L. (1983a) Effect of treating ovariectomized guinea-pigs with estradiol and progesterone on basal and A23187-stimulated release of prostaglandins from the uterus superfused in vitro. Prostaglandins, Leuk. \& Med. 11, 345-360.

Poyser, N.L. (1983b) Differential stimulation of prostaglandin and thromboxane synthesizing capacities in the guinea-pig uterus and ovary. Prostaglandins, Leuk. \& Med. 10, 163-177.

Poyser, N.L. (1984) Effect of using calcium-free Krebs solution on basal and A23187-stimulated prostaglandin output from the Day 15 guinea-pig uterus superfused in vitro. Prostaglandins, Leuk. \& Med. 13, 259269.

Poyser, N.L. (1985) Effect of trifluoperazine, a calmodulin antagonist, on prostaglandin output from the guinea-pig uterus. J. Reprod. Fert. 73, 295-303.

Poyser, N.L. \& Brydon, L.J. (1983) Prostaglandin release from the guinea-pig uterus superfused in vitro. Effect on stage of estrous cycle, progesterone, estradiol, oxytocin and A23187. Prostaglandins 25, 443-456.

Poyser, N.L. \& Scott, F.M. (1980) Prostaglandin and thromboxane production by the rat uterus and ovary in vitro during the oestrous cycle. J. Reprod. Fert. 60, $33-40$.

Riley, S.C. \& Poyser, N.L. (1987) Prostaglandin production by the guinea-pig endometrium: is calcium necessary? J. Endocr. 113, 463-471.

Schrey, M.P. \& Read, A.M. (1986) Phorbol ester stimulates phospholipid turnover in human amnion and decidual cells. J. Endocr. 111, Suppl., Abstr. 147.

Schrey, M.P., Read, A.M. \& Steer, P.J. (1986) Oxytocin and vasopressin stimulate inositol phosphate production in human gestational myometrium and decidual cells. Biosci. Reports 6, 613-619.

Skinner, S.J.M., Liggins, G.C., Wilson, T. \& Neale, G. (1984) Synthesis of prostaglandin F by cultured human endometrial cells. Prostaglandins 27, 821-838.

Swan, G.C. \& Poyser, N.L. (1983) Prostaglandin synthesis by, and the effects of prostaglandins and prostaglandin analogues on, the vas deferens of the rabbit and rat in vitro. J. Reprod. Fert. 69, 91-99.

Vogt, W. (1978) Role of phospholipase $A_{2}$ in prostaglandin formation. In Advances in Prostaglandin and Thromboxane Research, Vol. 3, pp. 89-95. Eds C. Galli, G. Galli \& G. Porcellati. Raven Press, New York. 